\title{
Strategic Coordination for Sustainable Investment in Critical Infrastructure
}

\author{
Jeremiah Mutamba, Ola Busari \\ Trans-Caledon Tunnel Authority, Centurion, South Africa \\ Email: jmutamba@tcta.co.za, obusari@tcta.co.za
}

Received November 2014

\begin{abstract}
In demonstrating the prime place of infrastructure investment in its national long-term development framework encapsulated in Vision 2030, as well as in the related New Growth Path, South Africa recently put together a comprehensive National Infrastructure Plan. Aside from mapping out short and medium-term priorities for scaling up investment in strategic sectors and enhancing infrastructure links across the country, the initiative underscores development objectives such as community empowerment and skills development. This paper zeroes into one of the 18 strategic programs in the plan-specifically devoted to water and sanitation infrastructure-and presents the principal elements for pursuing effective inter-project coordination and integration, as well as, ultimately, for ensuring the sustainable implementation of critical infrastructure. The approaches that have influenced the success of strategic coordination include participatory planning, project prioritization, regular tracking and unblocking of implementation hurdles, localization, active stakeholder engagement and ongoing program integration.
\end{abstract}

\section{Keywords}

Critical Infrastructure, Sanitation, South Africa, Strategic Coordination, Water

\section{Introduction}

South Africa's National Infrastructure Plan, a bold step for fast-tracking the strategic social and economic infrastructure for achieving the development and growth targets in the National Development Plan, seeks to galvanize partners to transform the structure of the economy and lay a strong foundation for higher and more inclusive growth. The long-term investment program is phased across 18 Strategic Integrated Projects (SIPs) spanning all nine provinces of the country. As a pointer to its high profile, the infrastructure build program is overseen by a Presidential Infrastructure Coordinating Commission (PICC), with associated secretariat and management structures. In turn, the PICC assigns specific state-owned enterprises the lead coordination role for each SIP. The PICC (2012) describes the core objectives of the SIPs initiative as unlocking opportunities, transforming the economic landscape, opening up new employment, enhancing the delivery of basic services, and fostering the integration of regional economies across the African continent.

The water and sanitation SIP consists of prioritized sector projects across the country. The central objective of the program is to ensure a sustainable supply of water to meet social needs and support economic growth, as 
well as providing a comprehensive sanitation service that enhances community wellbeing, reduces health care costs and improves economic productivity. Essentially, the program includes interventions straddling the full water value-chain, that is, from source to tap and back to source, including targeted efforts to address the water and sanitation backlogs estimated to be about 1.4 million and 2.1 million households, respectively.

Projects focus on the development of new infrastructure, rehabilitation and upgrading of existing infrastructure, as well as improving the management of water and sanitation infrastructure.

Indeed, water plays a critical and pivotal role in South Africa's socio-economic landscape, including driving agriculture, energy, mining, industry, tourism, urban growth and rural development (Figure 1). The water sector faces a number of challenges that could, in part, be addressed by improved investment in infrastructure development. Firstly, the country is water-stressed, and water resource availability to meet national demand varies from season to season. Secondly, demand for water continues to grow across all the competing economic sectors-putting severe pressure on the limited resource. Thirdly, the South African water supply system loses large amounts of water, exacerbating the pressure on the resource and inflicting supply challenges. Lastly, national spend on water (and sanitation) infrastructure has lagged behind the desired investment levels, as government attempted to balance competing national priorities.

This paper provides an overview of the country's water and sanitation sector, so as to highlight the significance of the SIP program to national development imperatives; characterizes the components of the particular infrastructure program; and presents the key strategies adopted for ensuring the effectiveness of inter-project integration and coordination.

\section{Background: Water and Sanitation Setting}

\subsection{Water Resources Availability}

It is well documented in the literature that South Africa is a water-stressed country-notably the world's 30th driest country. Two thirds of South Africa is semi-arid, with an average annual rainfall of $420 \mathrm{~mm}$ which is less than half the global average. Also, geographic variability in rainfall intensity and magnitude results in various parts of the country experiencing periodic droughts. The then Department of Water Affairs and Forestry reported in 2004 that, as of the year 2000, South Africa enjoyed an overall surplus of about $186 \mathrm{Mm}^{3}$ in water resources (DWAF, 2004), but had deficits in 10 of the then previously demarcated 19 water management areas (WMAs). The water availability situation was, however, updated in 2011 to five WMAs in deficit (as of 2000)

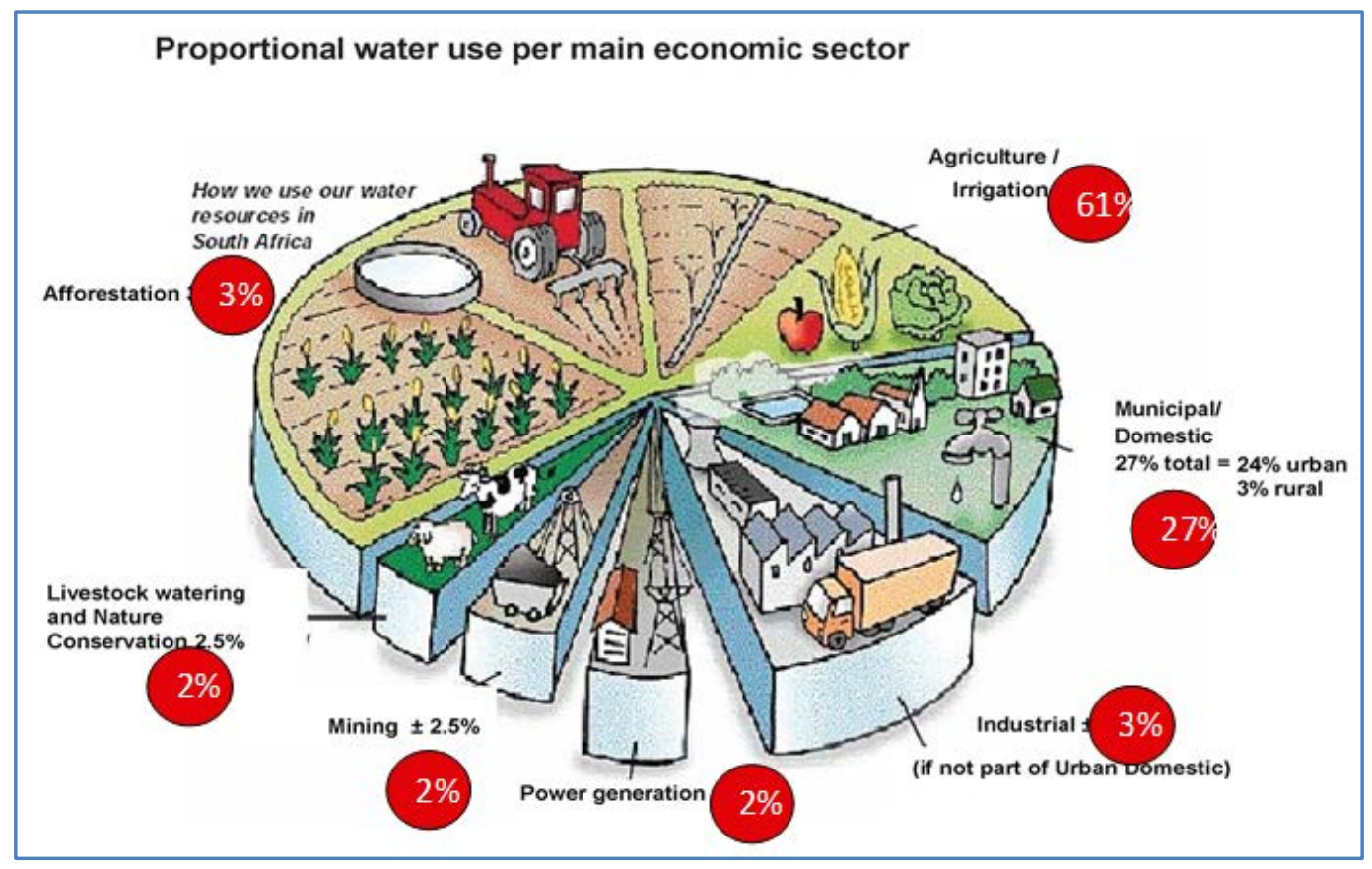

Figure 1. Water use by main economic sector (Source: DWA, 2013). 
and 10 WMAs in balance (DWA, 2011). The latest edition of the National Water Resources Strategy (DWA, 2013) notes that, while the country enjoyed a water resources surplus in 2000, it is now critical to bring about a mix of resources to reconcile demand and supply.

Addressing the water resource challenges requires that the country invest in strategic water infrastructure (both new and rehabilitation) and apply innovative strategies to bridge any potential resource gaps. As demand has grown over time, it is conceivable that the supply/demand balance is getting poorer with time. The required infrastructure investments include construction of new storage facilities (dams) and bulk water transfer schemes from areas of surplus to areas in deficit to manage supply/demand imbalances.

\subsection{Water Demand}

DWA (2013) advises that national water demand is projected to grow at $1.2 \%$ per annum over the next ten years. This statistic, however, clouds sector-specific water demand escalation, as demand has been growing rapidly in areas such as the domestic sector. Over the past ten years, water consumption in the domestic sector increased from $22 \%$ to $27 \%$ of the total resource (DWA, 2013). The United Nations Food and Agriculture Organization also estimates that South Africa's municipal water use per capita rose by 38\% between 1995 and 2005 . At this rate of demand growth, it is estimated that, between 2025 and 2030, demand could outstrip supply.

As the growing demand for water in South Africa is driven by population growth, improved livelihoods, and economic growth and development, meeting demand will be constrained by continued pollution of freshwater resources - a phenomenon that has the effect of reducing sustainable yield. Studies show that about $82 \%$ of rivers are threatened, while $44 \%$ are considered critically endangered. The poor health of rivers in South Africa is mainly attributed to urban and industrial effluent discharge into river systems, poorly maintained wastewater treatment works, salinity from irrigation return flows, acid mine drainage and inadequate sanitation facilities mostly in informal settlements. Consideration should also be given to the negative effects of climate change and unsustainable land use on the country's sustainable yield.

\subsection{Water Infrastructure}

Taking an upstream view, water resources infrastructure is bulk in nature and is developed to exploit the water resource in rivers to supply households, major industries, and agriculture-essentially bulk infrastructure. Figure 2 illustrates the various infrastructure components of the water value system. Water resources infrastructure includes dams, tunnels, pump-stations and large transfer systems (pipelines) designed mainly to abstract raw water from the water resource. Given that South Africa is characterized by periods of drought which can be prolonged, there is a need for large storage reservoirs to militate against drought periods and to ensure continual water supply. The country has, therefore, invested in several storage dams and inter-basin transfer schemes to transfer water from areas of abundance to areas of deficit.

South Africa has over 4700 dams, including those owned by the government and those built privately (DBSA, 2012). Government owns about 300 large dams with a total capacity of 29.2 billion $\mathrm{m}^{3}$, which account for $70 \%$ of the total dam capacity in the country. The rest of the country's water infrastructure serves to treat and distribute water to points of use, either through external connecting pipelines or through internal pipe networks.

Current challenges facing the water infrastructure system include: under-investment, aging infrastructure, insufficient capacity to capture and distribute the resource (National Treasury, 2012), and poor maintenance. The majority of South Africa's water resources infrastructures were constructed more than 40 years ago, and many may be approaching the end of their design lives. These challenges are compounded by shortages in managerial and technical skills in the institutions mandated to manage water infrastructure.

\subsection{Infrastructure Investment}

From a service delivery perspective, South Africa's access to piped water inside dwellings improved from $61 \%$ in 1996 to 73\% in 2011. Over the same period, the proportion of households without access to clean water fell from 20\% to 9\% (National Treasury, 2013). However, expanded access, combined with a lack of infrastructure maintenance, has strained existing infrastructure.

The importance of water availability traverses both social and economic fronts. As such, it is essential that South Africa has a reliable and sustainable water infrastructure (and sound water management) to support both 


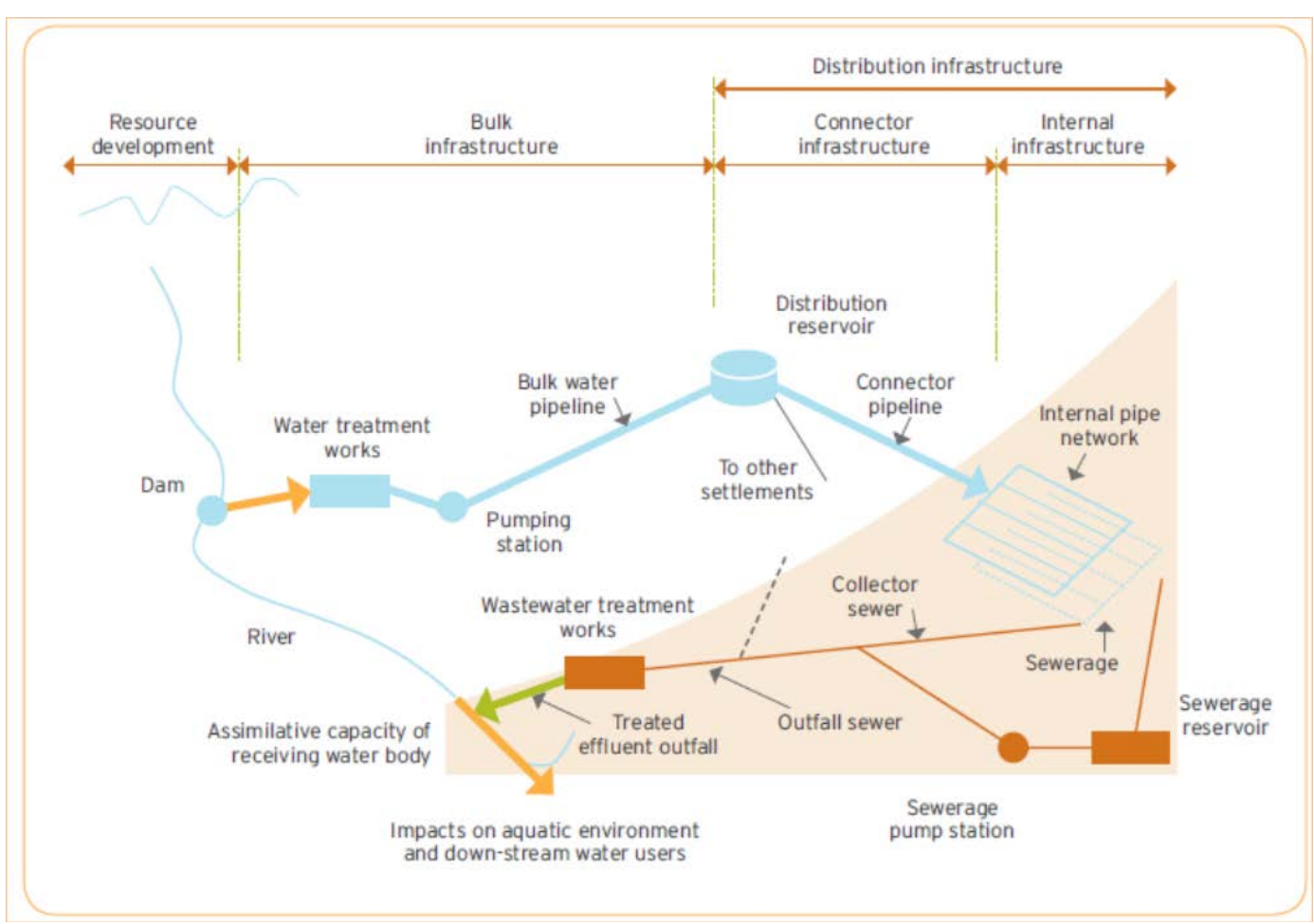

Figure 2. Components of the water infrastructure (Source: Balzer, 2011).

economic and social development as such initiatives may otherwise be constrained by uncertain water security, poor resource quality and associated water management challenges.

Planning for long-term infrastructure investment in the water sector is at the fore of the developmental agenda of government in South Africa, as evidenced by the recent documentation of a decadal water sector investment framework for the country (DWA, 2012). Closely related to that initiative is the continuing effort to determine an optimal model for financing and sustaining the expansion of water infrastructure in a manner that ensures that water services remain affordable to all of society.

\subsection{Sanitation Services}

South Africa has made significant strides in improving access to adequate sanitation since the new democratic dispensation in 1994. National sanitation coverage has grown rapidly from 48\% in 1994 to $79 \%$ in 2010 (DWA, 2010). However, about $11 \%$ of households in the country still have to be provided with meaningful sanitation services - these households form the group that has never had proper sanitation services before. An additional $26 \%$ of households within formal settlements have sanitation services which do not meet minimum standards. This situation is due to the deterioration of infrastructure caused by lack of technical capacity to ensure effective operation, timely maintenance, refurbishment and/or upgrading, pit emptying services and/or insufficient water resources.

From a programmatic perspective, the sanitation needs in South Africa can be summarized as a combination of the following elements:

- Service delivery backlogs for people who have never been served.

- Backlogs in the refurbishment of sanitation infrastructure that has deteriorated beyond regular maintenance requirements.

- Backlogs in the extension of existing infrastructure that needs to be extended to provide service to new households in the communities.

- Upgrades required for infrastructure that does not meet the minimum standards.

- Consolidation of institutional node for coordinating previously fragmented mandates for sanitation.

Until recently, the responsibility for sanitation in South Africa was fragmented, as it resided in various government departments, including: the former Department of Water Affairs, Department of Cooperative Gover- 
nance and Traditional Affairs, Department of Human Settlements, Department of Health, and Department of Public Works. Initially, from 1994 to 2001, the responsibility for sanitation services at national and provincial levels rested with the then Department of Water Affairs and Forestry. However, in 2001, the municipal monitoring function was moved to the Department of Provincial and Local Government via the Municipal Infrastructure Grant funding instrument. Also, in 2009 the National Sanitation Program Unit was moved from DWAF to the Department of Human Settlements, but DWAF retained certain responsibilities, including regulation, information management, high-level planning and management of the Bulk Infrastructure Grant. Currently, responsibility for sanitation at provincial level rests with the Department of Human Settlements, with certain links to the Departments of Health, Education and Public Works. In order to address the state of fragmentation and the lack of a single national body taking the lead in sanitation, South Africa has now established a new Department of Water and Sanitation, pointing to a fresh direction for more effective coordination and the upholding of sanitation norms and standards.

\section{The Infrastructure Program}

The SIP-18 program is designed to address a greater portion of the water and sanitation challenges articulated in the preceding sections. It is a water and sanitation infrastructure program comprising six inter-related infrastructure sub-programs, namely: national water resources infrastructure (NWRI), regional bulk infrastructure (RBIG), municipal infrastructure grant (MIG), municipal water infrastructure grant (MWIG), water boards capital projects, and metropolitan municipality capital projects. The nature and composition of the six SIP-18 program categories are described in the sections to follow.

\subsection{National Water Resources Infrastructure}

This group of water infrastructure projects responds to water needs predominantly at the national level. Projects in this category are conceptualized, initiated, planned, designed and implemented with direct influence from the Department of Water Affairs and Sanitation (DWS). These projects can be funded either through the fiscus (for socially-inclined projects) or off-budget (for projects that are commercially bankable). Projects in this category include large dams, transfer pipelines and pump stations.

\subsection{Regional Bulk Infrastructure}

This infrastructure type is required to connect the water resources, on a macro or sub-regional scale (over vast distances), with internal bulk and reticulation systems. "Macro" is defined as infrastructure serving extensive areas across multi-municipal boundaries. "Sub-regional" is defined as large bulk infrastructure serving numerous communities over a large area, normally within a specific district or local municipal area. Regional bulk water infrastructure plays a key role in bringing water services to all people in South Africa, and is critical in achieving integrated socio-economic development. Funding for RBIG projects comes from the National Treasury and is channeled through the DWS. These projects are implemented by the nine regional offices of the DWS, with oversight from the national office.

\subsection{Municipal Services Infrastructure}

The municipal infrastructure grant is a funding arrangement that combines all the previous capital grants for municipal infrastructure into a single consolidated grant. The previous disparate infrastructure grants were managed by a number of departments in an uncoordinated manner. MIG projects address basic levels of service and focus on providing services to the poor. For example, a basic water supply facility refers to infrastructure necessary to supply 25 liters of potable water per person per day within 200 meters of a household, which is equivalent to 6000 liters of potable water supplied per formal connection per month. This level of water supply, in the context of the ladder of service provision, is characterized as free basic water in South Africa. MIG projects are managed by the Department of Cooperative Governance, and municipalities play a central role in the planning, development and delivery of the infrastructure in their jurisdictions.

\subsection{Municipal Water Infrastructure}

The MWIG program is aimed at addressing backlogs in water provision for communities without previous 
access to water. The program is designed to assist resource-poor District Municipalities to provide water supply services to consumers currently without services, particularly those in rural areas. All MWIG projects are located within 23 municipal districts identified as priority. A technical team comprising representatives from DWS, Department of Cooperative Governance, Water Boards, District Municipalities and the Municipal Infrastructure Support Agency is mandated to approve all project designs and interventions with a cost in excess of R20 million.

\subsection{Other Strategic Infrastructure}

Classified as other strategic infrastructure are projects that are financed by the capital budget of the big metropolitan municipalities and water boards. It is notable that projects in this cluster exclude water and sanitation projects falling into any of the categories previously described.

\section{Elements of Strategic Coordination}

In the pursuit of effective inter-project coordination and integration, to ensure the sustainable implementation of critical water and sanitation infrastructure, the SIP has deployed a number of strategies, as follows:

- Sector-wide consultative development of an infrastructure master plan;

- Prioritization and fast-tracking of critical projects;

- Regular progress tracking and reporting;

- Promotion of industrialization and localization;

- Active stakeholder engagement;

- Ongoing program integration.

\subsection{Consultative Development of Master Plan}

The first task involves the development of a comprehensive database of government-sponsored and initiated water and sanitation infrastructure projects-the infrastructure master plan. The objective of developing an infrastructure master plan, jointly with all strategic sector stakeholders, is to bring together, in one document or repository, the full set of projects that the government is planning or already implementing, both for information purposes as well as for better tracking and monitoring. These projects are located across the country and are initiated by national and provincial departments, metro, district and local municipalities, and water boards. The projects are at different phases in the life-cycle, including: conceptual, planning, pre-feasibility, feasibility, and construction.

\subsection{Prioritization \& Fast-Tracking of Critical Projects}

One of the key drivers of the SIPs programs is the government's intention to ensure successful and timely completion of critical infrastructure projects. Given the track record of delays in several government projects, it is important for all parties involved in strategic projects to see to it that projects are completed on time, within budget and to specification - thus breaking from the trend of poor project delivery. Where practically possible, project partners are required to accelerate project implementation to bring forth early project completion and service delivery to target communities. The SIP coordinator, in collaboration with key project partners, identifies possible projects that can be fast-tracked and have their project schedules revised accordingly to reflect time savings. Such projects are then tracked and monitored to ensure delivery in the revised timeframes. The SIP coordinator is also tasked with reporting on progress, challenges and proposed mitigation measures.

\subsection{Progress Tracking and Reporting}

A natural SIP program task involves the tracking and monitoring of both the program and its constituent projects. Progress is tracked and captured quarterly, in a report, for submission to the Presidential Infrastructure Coordinating Commission. Key issues tracked include: expenditure against budget, project highlights, key project challenges, number of jobs created, localization levels within projects, and technical progress. Given the number of projects in the SIP-18 program, it is not practical to centrally track each and every project from a coordination office. Considering this challenge, the SIP coordinator tracks progress at sub-program level, with a focus on 
overall progress, expenditure, and key challenges for each cluster of projects. As part of the tracking, the SIP coordinator also investigates and makes recommendations in cases of missed targets and opportunities to accelerate strategic projects.

\subsection{Promoting Industrialization and Localization}

Like projects in other SIP programs, SIP-18 projects are expected to support and promote localization and industrial development in the country. Therefore, on an ongoing basis, the SIP coordinator identifies localization opportunities in SIP-18 projects, as well as collaboratively work, with key project partners, the PICC, the Industrial Development Corporation and other related institutions to promote localization in SIP-18 projects.

\subsection{Stakeholder Engagement}

Given its national appeal, SIP-18 has a number of diverse stakeholder groupings-from both the water sector and the sanitation sector. Key stakeholder groupings include government departments, local authorities (district and local), metropolitan municipalities, water user associations, industry, water boards, and other organizations such as the South African Local Government Association. Each of these institutions has members whose daily work revolves around the planning, design, construction, management, as well as operation and maintenance of water and sanitation infrastructure. The combined sector also receives considerable support and attention from civil society, non-governmental organizations and funding institutions - which, by extension, form part of the sector's stakeholder groups.

To engender participatory coordination, the SIP coordinator closely engages all the key stakeholders, soliciting their inputs towards the coordination of the program. While the coordination process acknowledges and gives due credence to the importance of broad stakeholder engagement, the SIP coordinator strives to balance engagement with value creation. In actively working with key stakeholders, the SIP coordinator uses a number of platforms as follows:

- Convening one Inter-Governmental Forum (IGF) per year-bringing together political leadership and technical experts on a single platform to deliberate on and resolve strategic issues. The IGF is chaired by the Minister responsible for SIP-18 (IGF chair) and, therefore, provides political direction for program coordination.

- Facilitating Program Technical Forums at quarterly intervals-involving key project partners to work on project issues and challenges, as well as formulating solutions to unique project hurdles.

- Arranging project-centered sessions-where necessary, the SIP coordinator also convenes meetings with specific project partners with strategic requirements and challenges, to explore options for early resolutions and fast-tracking, including pointers to synergistic partnerships for value-add.

\subsection{Ongoing Program Integration}

The SIP-18 program interfaces with 10 of the other 17 SIP programs. Each of these ten SIPs has water and/or sanitation projects, either as dedicated water and sanitation projects or as ancillary service projects designed to support developmental activities in the program area. SIP-18 can, therefore, be regarded as cross-cutting, and its coordination could not be conducted in isolation. Rather, it is undertaken in close collaboration with other coordinating entities, taking due consideration of their proposed inputs, interventions, initiatives, and recommended strategies.

For effective integration, the SIP-18 coordinator works closely with the other SIP coordinators and, where appropriate, exchanges information and strategies on an ongoing basis. SIP-18 also holds joint technical forums with other coordinators to ensure uniform information capture and dissemination among key stakeholders, as well as avoid information asymmetries. Similarly, SIP-18 supports the other coordinators in their direct coordination roles.

\section{Conclusion}

The primary thread running through the strategic coordination of the long-term investment program in water and sanitation infrastructure is the unblocking of obstacles that may impact on the efficient implementation of critical projects. With support from the Presidential Infrastructure Coordinating Commission, as deemed appropriate, 
the SIP coordinating node, in the form of a state-owned enterprise, provides assistance to key project partners and their implementing agents to fast-track identified aspects of projects. The effectiveness of coordination is indexed across five dimensions: quality, time, cost, stakeholder relations and communication.

In undertaking its coordinating function, the state-owned enterprise responsible for the water and sanitation SIP regularly tracks and monitors progress on the identified key milestones for each project, and compares progress against benchmarks provided in project implementation plans and charters. Trends on progress and dashboard views are also generated to provide a dynamic and broader picture of project performance. The performance results are captured in progress reports that are submitted to the PICC on a quarterly basis. However, in instances where a project demands special attention, a status review is conducted according to the project's situation and a special report is developed for the PICC.

Strategic coordination and reporting are reinforced by broad stakeholder participation throughout the year, drawing on an annual Inter-Governmental Forum involving political leadership, quarterly Program Technical Forums, and regular project-specific sessions for resolving emerging challenges.

\section{References}

Balzer, T. (2011). Water Infrastructure Investment Framework: Setting the Scene. Presentation at the Department of Water Affairs Indaba, Pretoria, 14-15 June.

DBSA (2012). The State of South Africa’s Economic Infrastructure: Opportunities and Challenges. Johannesburg: Development Bank of Southern Africa.

DWA (2010). Strategic Overview of the Water Sector. Pretoria: Department of Water Affairs.

DWA (2011). Water for Growth and Development Framework (Version 1). Pretoria: Department of Water Affairs.

DWA (2013). National Water Resources Strategy (2nd ed.). Pretoria: Department of Water Affairs.

DWAF (2004). National Water Resources Strategy. Pretoria: Department of Water Affairs and Forestry.

Frankova, E. \& Johanisova, N. (2008). Economic Localization in the Context of Sustainable Rural Development. http://www.academia.edu/

National Treasury (2012). Budget Review 2012. Pretoria: Government of South Africa.

National Treasury (2013). Budget Review 2013. Pretoria: Government of South Africa.

PICC (2012). A Summary of the South African National Infrastructure Plan. Pretoria: Presidential Infrastructure Coordinating Commission. 